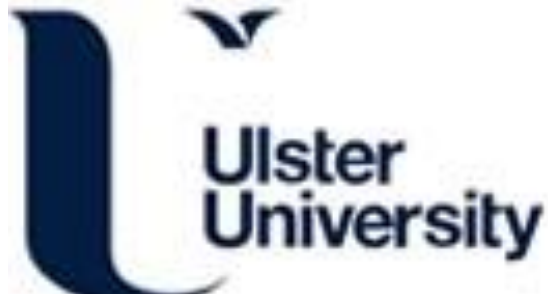

\section{A novel core-shell nanofiber drug delivery system intended for the synergistic treatment of melanoma}

Zhu, L. F., Zheng, Y., Fan, J., Yao, Y., Ahmad, Z., \& Chang, M. W. (2019). A novel core-shell nanofiber drug delivery system intended for the synergistic treatment of melanoma. European Journal of Pharmaceutical Sciences, 137, [105002]. https://doi.org/10.1016/j.ejps.2019.105002

Link to publication record in Ulster University Research Portal

Published in:

European Journal of Pharmaceutical Sciences

Publication Status:

Published (in print/issue): 01/09/2019

DOI:

10.1016/j.ejps.2019.105002

Document Version

Author Accepted version

\section{General rights}

Copyright for the publications made accessible via Ulster University's Research Portal is retained by the author(s) and / or other copyright owners and it is a condition of accessing these publications that users recognise and abide by the legal requirements associated with these rights.

\section{Take down policy}

The Research Portal is Ulster University's institutional repository that provides access to Ulster's research outputs. Every effort has been made to ensure that content in the Research Portal does not infringe any person's rights, or applicable UK laws. If you discover content in the Research Portal that you believe breaches copyright or violates any law, please contact pure-support@ulster.ac.uk. 


\title{
A novel core-shell nanofiber drug delivery system intended for the synergistic treatment of melanoma
}

\author{
Li-Fang Zhu ${ }^{\text {a,b }}$, Yufei Zheng ${ }^{c}$, Jiannan Fan ${ }^{\text {a,b }}$, Yuanfa Yao ${ }^{\text {a,b }}$, Zeeshan Ahmad ${ }^{d}$, \\ Ming-Wei Chang a,b, e* \\ ${ }^{a}$ Department of Biomedical Engineering, Key Laboratory of Ministry of Education, Zhejiang \\ University, Hangzhou 310027, P.R. China. \\ ${ }^{\mathrm{b}}$ Zhejiang Provincial Key Laboratory of Cardio-Cerebral Vascular Detection Technology and \\ Medicinal Effectiveness Appraisal, Zhejiang University, Hangzhou 310027, P.R. China. \\ ${ }^{\mathrm{c}}$ College of Animal Sciences, Zhejiang University, Hangzhou, 310058, P.R. China \\ ${ }^{\mathrm{d}}$ Leicester School of Pharmacy, De Montfort University, The Gateway, Leicester, LE1 9BH, UK. \\ ${ }^{\mathrm{e}}$ Nanotechnology and Integrated Bioengineering Centre, University of Ulster, Jordanstown \\ Campus, Newtownabbey, BT37 0QB, Northern Ireland, UK.
}

\section{Corresponding author}

*Email: mwchang@zju.edu.cn. Tel: +86(0)571-87951517. 


\begin{abstract}
Here, we introduce core-shell nanofibers based on chitosan (CS)-loaded poly ( $\varepsilon$ caprolactone) (PCL) shell and 5-fluorouracil (5-FU)-loaded Poly( $N$-vinyl-2pyrrolidone) (PVP) core for synergistic therapy of melanoma skin cancer. The yielded nanofibers exhibited an average diameter of $503 \mathrm{~nm}$ with high drug-encapsulating efficiency and good mechanical properties. Moreover, the burst release of 5-FU significantly inhibited melanoma skin cancer cells (B16F10 cells), and the sustained release of CS exhibited "remedying effects" on normal skin cells (L929 cells) after suffering adverse effects from 5-FU treatment. For the B16F10 cells, the early apoptosis cells increased from $0.8 \%$ to $62.2 \%$ after being treated with blended films loaded with 5-FU ( $2 \mathrm{wt} \%$ ) for $24 \mathrm{~h}$; for the L929 cells, the vital cells increased from $68.9 \%$ to $77.0 \%$, and the early apoptosis of stage cells decreased from $12.3 \%$ to $10.9 \%$ after being treated with blended films with CS (8 wt\%) for $24 \mathrm{~h}$. In conclusion, the results introduced in this work can be a promising strategy for cancer treatment and possesses synergism potential to broaden an avenue for chemotherapeutic therapy with minimum adverse effects on normal cells.
\end{abstract}

Keywords: skin cancer; chitosan; 5-fluorouracil; core-shell nanofiber; controlled release. 


\section{Introduction}

Skin cancer is one of the most common and aggressive neoplasms with cutaneous melanoma being responsible for approximately $75 \%$ of all deaths induced by skin cancer (Esteva et al., 2017). The incidence of this melanoma is increasing especially in Western countries (Gray-Schopfer et al., 2007). Some factors in daily life will induce the incidence of melanoma, such as overdose of ultraviolet (UV) radiation, alcohol consumption as well as family history, immune suppression and gene polymorphisms (Sabitha et al., 2013). Although various treatments of melanoma are developed, such as chemotherapy, surgical resection, and immunotherapy, the cure rate still needs to be improved further (Ma et al., 2017). To inhibit the cancer cell growth and aggressiveness, 5-Fluorouracial (5-FU) is one of the common agents used in chemotherapy due to effective inhibition and extermination effects against skin cancer (Longley et al., 2003). 5-FU works by inhibiting thymidylate synthase and incorporation of its metabolites (fluoronucletides) into RNA and DNA (Longley et al., 2003). 5-FU is conventionally applied in solutions at the various concentration $(1 \%, 2 \%$, and $5 \%)$ or creams $(0.5 \%$, $1 \%$, and 5\%) (Khan et al., 2015).

Transdermal delivery of drugs has been suffered by poor penetration in the deeper skin layers due to the poor penetration concerning the transdermal drug delivery (Lee et al., 2016). Various approaches have been developed to overcome the stratum corneum barrier and improve drug accumulation at the targeting area. For example, using microneedles (Prausnitz and Langer, 2008) or nanoparticles (Wang et al., 2011) as drug carriers can aid drug penetration into the deeper layers of the skin compared to more conventional drug deliveries (e.g. solutions, creams). Another approach to aid this is to improve the therapeutic effect by controlling the drug release period. By using solid-lipid nanoparticles (Shah et al., 2011) and core-shell nanofibers (Chen et al., 2015) and encapsulating drugs into the lipid matrix or into the core, it is possible to control drug release rate via altering the solid-to-lipid or core-to-shell ratio. There is research that has shown significant anti-proliferative effects against + SA mammary epithelial cells at low concentrations $(0.52 \pm 0.02 \mu \mathrm{M})$ (Ali et al., 2010). Despite this, the adverse effects of 5-FU on normal health cells (e.g. hair loss, liver disorders) should not be 
neglected (Rezaei et al., 2018). Hence, extra recovery therapy following 5-FU treatment to minimize long term side-effects and impairment of normal heath tissue cells around the targeting is critical on synergism skin cancer treatments.

Nano-scaled core-shell ultrafine fibers (combining excellent properties of two components) can incorporate bioactives within the core-shell structure and provide improved advantages regarding biocompatibility, super-hydrophobicity, and mechanical properties (Chen et al., 2015). Moreover, large proportion of dual drugs can be efficiently co-encapsulated in single-step preparation attributing to high surfacearea-to-volume ratio (Jia et al., 2017). As a result, nanofibers with core-shell structures have demonstrated excellent property with respect to encapsulating two agents in separate regions of the same carrier simultaneously, exhibiting enhanced therapeutic effects (Kamel et al., 2017; Seyednejad et al., 2012). Coaxial electrospinning (CO-ES), composing of two or more concentric nozzles, has shown efficiency and versatility in the fabrication of core-shell fibers (Sun et al., 2003). Driven by a high-voltage electrostatic field combined with a gravitational field, CO-ES has been used to fabricate micro- and nano-complex structures on-demand in a one-step process (Forward et al., 2013; Zhou et al., 2012). Due to its versatility and not requiring harsh processing conditions (e.g. high temperatures), it overcomes the limitations seen with more conventional methods such as hot-melt extrusion and single-nozzle ES (Jia et al., 2017). In addition to this, some novel and multi-functional properties, such as controlled drug release, functionalized fiber surface (Sun et al., 2006) and targeted drug delivery (Jia et al., 2017) have been demonstrated via CO-ES technique.

Chitosan (CS) is a derivative yielded following deacetylation of chitin. During this process, the N-acetyl-D-glucosamine (GlcNAc) unit in chitin is converted to Dglucosamine (GlcN) unit, forming chitosan (Cho et al., 2000). Due to its biocompatibility, non-toxicity, and biodegradability (Kurita, 2006), chitosan has been used as a key material for drug delivery (Dev et al., 2010) and in healthcare engineering (Ragetly et al., 2010). Moreover, the significant improvement of fibroblast cells (L929 cells) proliferation has been revealed (Zhu et al., 2019). However, its inherent poor solubility and polycationic character limits the electro-spinnability of chitosan. This 
can be improved by blending with other polymers such as polylactic acid (PLA) and polyvinyl alcohol (PVA) (Chen et al., 2015).

Poly ( $\varepsilon$-caprolactone) (PCL) has also gained increasing interest in drug delivery, surgery sutures, and fibrous scaffolds due to its biodegradability and excellent biocompatibility (Ruckh et al., 2010). Poly(N-vinyl-2-pyrrolidone) (PVP) has conventionally been used as a filler component and has previously been blended with other polymers. It is widely used for its biocompatibility and its solubility in water and most organic solvents (Kim et al., 2013). It was found that after being blended with PVP, the diffusion of water into the PCL chains was improved and the hydrolytic degradation of blending mixture was accelerated (García Cruz et al., 2009; Yu et al., 2006).

In the present study, blending nanofibers of PCL/PVP with core-shell structure was fabricated via CO-ES. The PCL/chitosan was used as shell layer, and PVP (encapsulating 5-FU) was used as the core layer. PCL/PVP nanofibers were studied using imaging (SEM), spectroscopy (FT-IR) and X-ray diffraction (XRD). In vitro drug release results indicated the burst release of 5-FU first inhibited the cutaneous melanoma cell proliferation and the subsequent sustained release of chitosan protected the normal cell from the accidental injury of 5-FU. Thus, synergetic cancer treatments by minimizing the negative effects of 5-FU on normal cells and inhibiting the skin cancer cells growth is demonstrated in the work presented here.

\section{Materials and methods}

\subsection{Materials}

PCL $\left(\mathrm{Mw}=8 \times 10^{4} \mathrm{~g} / \mathrm{moL}\right)$, PVP $\left(\mathrm{Mw}=1.3 \times 10^{6} \mathrm{~g} / \mathrm{moL}\right)$ were purchased from Sigma-Aldrich (St Louis, USA). CS (degree of deacetylation $=81 \%, \mathrm{Mw}=8908$ $\mathrm{g} / \mathrm{moL}$ ) was prepared according to previous work (Zhu et al., 2019). 5-FU was purchased from Solarbio (Solarbio Science \& Technology Co., Ltd., Beijing, China). Ethanol (100\%), Dimethylsulfoxide (DMSO), and acetic acid were purchased from Sinopharm (Sinopharm Chemical Reagent Co., Ltd., Shanghai, China). Modified eagle medium (MEM), Dulbecco's modified eagle medium (DMEM) was obtained from 
Gibco (Gibco, Carlsbad, California, USA); and fetal bovine serum (FBS) was obtained from Sijiqin (Sijiqin, Hangzhou, China). Deionized water (DI) was obtained from ultrapure water purifier (Millipore Milli-Q, Bedford, USA). All chemicals and reagents of analytical grade.

\subsection{Preparation of electrospinning solutions}

PCL solution (18 wt\%) was prepared by dissolving PCL in acetic acid while PVP solution $(18 \mathrm{wt} \%)$ was prepared by dissolving PVP in ethanol. Chitosan at various concentrations was dissolved using $400 \mu \mathrm{L}$ mixture solution of acetic acid and DI water (50: 50, v/v) as shown in Table 1. 5-FU was added in $250 \mu \mathrm{L}$ DMSO to obtain $2 \mathrm{wt} \%$ (weight of PVP) solution. To form homogeneous polymer solutions, the initial mixtures were stirred (ca. $300 \mathrm{rpm}$ ) constantly for $8 \mathrm{~h}$ at ambient temperature $\left(24^{\circ} \mathrm{C}\right)$ using a magnetic stirrer (VELP ARE heating magnetic stirrer, Italy). The chitosan solution and 5-FU solution were then added to the PCL solution and PVP solution, respectively, and were stirred for $1 \mathrm{~h}$ before electrospinning.

\subsection{Fabrication of PCL-CS/PVP-5-FU nanofibers using CO-ES}

The CO-ES apparatus used in this work is shown in Fig. 1a. The set-up consists of a high power voltage supply (Glassman High Voltage Inc. series FC, USA), two syringe pumps (KD Scientific KDS100, USA), the inner and outer needles having internal/external diameters of 0.2/0.4 and 0.9/1.2 mm, respectively. The resulting PCLCS solution was loaded in a $5 \mathrm{~mL}$ syringe and perfused into the outer needle using a syringe pump with a flow rate of $0.6 \mathrm{ml} / \mathrm{h}$ while the PVP-5-FU solution was perfused into the inner needle with a flow rate of $0.2 \mathrm{ml} / \mathrm{h}$. A grounded roller approximately 14 $\mathrm{cm}$ long and $7 \mathrm{~cm}$ in diameter at rotating speed of ca. $650 \mathrm{rpm}$ was used to collect the resulting spun fibers. To generate nanofibers, a high voltage $(15.5-17.5 \mathrm{kV})$ was applied between the coaxial needle and roller, and the distance between the roller and needle tip was $\sim 10 \mathrm{~cm}$ vertically at ambient temperature $\left(24^{\circ} \mathrm{C}\right)$. A series of fibers was prepared as detailed in Table 1. 


\subsection{Fiber morphology assessment}

The surface morphology of electrospun fibers was assessed via optical microscope (OM, phoenix BMC503-ICCF, China) and SEM (Quanta FEG650, FEI, Netherland). For SEM analysis, samples were coated with a layer of gold using a sputter-coater (108 Auto Cressington Sputter Coater, Ted Pella, Inc.) for $60 \mathrm{~s}$ with the current intensity of $25 \mathrm{~mA}$. The SEM images of samples were obtained at an accelerating voltage of $20 \mathrm{kV}$. The mean fiber diameters and fiber size distribution were quantified using 100 random fibers using ImageJ software (National institute of Health, MD, USA).

\subsection{Fourier transform infrared (FT-IR) spectroscopy}

The composition and chemical interactions of the core-shell nanofibers were analyzed using FT-IR spectroscopy (IR Affinity 1, Shimadzu, Japan). Each sample (ca. $2 \mathrm{mg}$ ) was mixed with $\mathrm{KBr}$ powder (ca. $200 \mathrm{mg}$ ) and compressed into transparent pellets using a powder compressing machine (FW-4A, Tianjin TUOPU instrument Co., Ltd, Tianjin, China) under pressure (ca. $20 \mathrm{MPa}$ ) for $2 \mathrm{~min}$. The FT-IR spectra of each sample was acquired within the scanning range $4000-400 \mathrm{~cm}^{-1}$ and resolution of $4 \mathrm{~cm}^{-}$ ${ }^{1}$ at an average of 20 scans.

\subsection{X-Ray Diffraction (XRD)}

The crystal configuration of electrospun fibers was analyzed using an X-ray diffractometer (Gemini A OHra, Oxford Varian, UK) at $25^{\circ} \mathrm{C}$. The samples were examined under the following conditions: $1^{\circ}$ of DivSlit and $10 \mathrm{~mm}$ of DivH.L. Slit, continuous scanning at the $2 \theta$ range $3-60^{\circ}$ with deploying step of $0.02^{\circ}$ and step speed of $5 \% \mathrm{~min}$. The analyzing voltage and current was $40 \mathrm{kV}$ and $30 \mathrm{~mA}$, respectively.

\subsection{Contact angle analysis}

The water contact angle (CA) of resulting films was measured using optical contact angle meter (SJ200KB, KINO Industry Co., Ltd., USA). The CA value of sample was obtained through sessile-drop mode at $25^{\circ} \mathrm{C}$. Briefly, a $1 \mu \mathrm{L}$ water droplet was dropped on the film sample and recording the CA. The mean CA results were obtained using 
three samples with triplicate measurements.

\subsection{Tensile test}

The mechanical strength of the resulting films was determined using a universal materials tester (Zwick/ Roell Z020, Zwick, Germany). Firstly, the films were shaped into dog-bone shaped matrices using standard shape (length $\times$ width $=7.5 \mathrm{~cm} \times 1.4 \mathrm{~cm}$ ). The thickness of each sample was then measured using a coating thickness gauge (PDCT1, Powered Technology (Beijing) Co., Ltd). Selecting gauge of $10 \mathrm{~mm}$ in length and load cell of $500 \mathrm{~N}$ was used to carry out tensile testing with the crosshead speed of 10 $\mathrm{mm} / \mathrm{min}$ at $25{ }^{\circ} \mathrm{C}$. Each sample type was assessed in triplicate and the mean tensile strength was obtained.

\subsection{Release study in vitro}

The loading capacity (LC) and encapsulation efficiency (EE) of CS or 5-FU were used to evaluate the encapsulating effect of the electrospinning process. According to the methods showed in previous work (Yao et al., 2017) with slight modifications. LC and EE were calculated using Eq. (1) and Eq. (2), respectively.

$$
\begin{aligned}
& \text { LC }(\%)=\frac{\text { Total amount of CS or } 5-\mathrm{FU} \text { content in fibers }(\mathrm{mg})}{\text { Amount of fibers }(\mathrm{mg})} \times 100 \% \\
& \text { EE }(\%)=\frac{\text { Total amount of CS or } 5-\mathrm{FU} \text { content in fibers }(\mathrm{mg})}{\text { Total amount of GLP added in polymer solution }(\mathrm{mg})} \times 100 \%
\end{aligned}
$$

Where, the total amount of CS or 5-FU content encapsulated in fibers was measured using UV spectrophotometer (UV-2600 spectrophotometer, Shimadzu, Japan) at a wavelength of $201 \mathrm{~nm}$ (Liu et al., 2006) and $265 \mathrm{~nm}$ (Khan et al., 2015) respectively; and measured by the fitting equations (Fig. S1a \& b) following fiber dissolution in acetic acid.

The release of encapsulated CS or 5-FU from the engineered fibers was measured using phosphate buffer solution (PBS) with $\mathrm{pH}=5.7 \pm 0.1$ to mimic melanoma cell micro-environment according to previous work (Sahu et al., 2017). Briefly, a sample of the films was immersed into a jar containing $10 \mathrm{~mL}$ PBS and was agitated using a Gasbathing Constant Temperature Vibrator (DDHZ-300, Suzhou Peiying experimental 
equipment Co., Ltd, Suzhou, China) at $100 \mathrm{rpm}, 37.5^{\circ} \mathrm{C}$. At pre-determined time points, $4.0 \mathrm{ml}$ of the release medium was removed and replaced with $4.0 \mathrm{ml}$ of fresh PBS. The concentration of released drug was obtained using the UV spectroscopy and fitting equations (Fig. S1a \& b). The percentage of the released CS or 5-FU was calculated using Eq. (3) (Yao et al., 2017):

Mass release $(\%)=\mathrm{m}_{\mathrm{t}} / \mathrm{m}_{\mathrm{s}} \times 100 \%$

Where, $\mathrm{m}_{\mathrm{t}}$ was the weight of released agent (CS or 5-FU) at time point $\mathrm{t}, \mathrm{m}_{\mathrm{s}}$ was the weight of agent (CS or 5-FU) encapsulated in the sample.

\subsection{Inhibitory effect on melanoma cell line}

L929 (mouse fibroblasts) and B16F10 (mouse melanoma cell) cells were used to evaluate the synergistic and anticancer effect of resulting fibers on normal and cancer cells, respectively. L929/B16F10 cells were cultured in MEM/DMEM supplemented with $10 \%$ FBS in culture dishes $(\Phi=10 \mathrm{~cm})$ at $37^{\circ} \mathrm{Cin}$ a humidified atmosphere of $5 \%$ $\mathrm{CO}_{2}$, and were grown to ca. $85 \%$ confluence prior to further treatment.

The cell viability was measured using a CCK-8 kit (cell counting Kit-8 reagent, Dojindo Laboratories, Kumamoto, Japan). Here, cells $\left(1.0 \times 10^{5}\right.$ cells $\left./ \mathrm{mL}\right)$ were seeded into 96-well plates and co-cultured with various concentration of 5-FU solution after being cultured for $24 \mathrm{~h}$. The 5-FU was dissolved into DMSO and then diluted to various concentrations using MEM/DMEM for the L929/B16F10 cells. After treatment with 5FU for $48 \mathrm{~h}$, the optical density (OD) was measured using a microplate reader (Spectra Max 190, NanoDrop, USA) at $450 \mathrm{~nm}$ after being incubated with $10 \mu \mathrm{L} \mathrm{CCK}-8$ solution for $4 \mathrm{~h}$. The cell viability was measured according to the CCK-8 kit manufacture instructions.

The effects of the resulting fibers on the cell cycle and apoptosis of cells were analyzed using Flow Cytometry Analysis (FACScalibur, Becton Dickinson, USA). Before treatment, the fibers were disinfected using UV irradiation for $2 \mathrm{~h}$. Equal numbers of cells $\left(2.0 \times 10^{5}\right.$ cells $)$ were co-cultured with resulting fibers (ca. $100 \pm 2 \mathrm{mg}$ ) in culture dishes $(\Phi=6 \mathrm{~cm})$ at standard cultural environment. At the pre-determined time points, the cells were harvested and washed twice with PBS (pH7.4) and then 
centrifuged at $1000 \mathrm{rpm}$ for 5 mins. The cells were then stained with Annexin V-FITC and PI (Apoptosis Detection Kit, Multi Sciences, Hangzhou China) and Cell Cycle Staining kit (Apoptosis Detection Kit, Multi Sciences, China) to detect apoptosis and cell cycle of cells, respectively.

To visualize the effects of fibers on apoptosis of cells a AO/EB dye mixture kit (Solarbio Life Science, Beijing, China) was used to evaluate the cell death mode.

Briefly, cells suspension $\left(1.2 \times 10^{5}\right.$ cells $)$ was seeded into a 6 -well plate and incubated for $24 \mathrm{~h}$. The fibers (ca. $100 \pm 2 \mathrm{mg}$ ) were added into each well and co-cultured at standard cultural environment. At pre-determined time points, the cells were harvested via trypsinization and washed twice with $\mathrm{PBC}(\mathrm{pH}$ 7.4) and were centrifuged at 1000rpm for 5 mins. The cells were suspended in $500 \mu \mathrm{L} \mathrm{PBS} \mathrm{(pH} \mathrm{7.4)} \mathrm{and} \mathrm{were} \mathrm{stained}$ using $20 \mu \mathrm{L} \mathrm{AO} / \mathrm{ED}$ dye mixture (AO: $\mathrm{EB}=1: 1 \mathrm{v} / \mathrm{v}$ ) for $10 \mathrm{mins}$ at $25^{\circ} \mathrm{C}$. A sample (ca. $10 \mu \mathrm{L}$ ) of the stained cell suspension was observed using Fluorescence Microscopy (Olympus, BX61W1-FV1000, Tokyo, Japan).

\subsection{Statistical analysis}

Results were expressed as mean \pm standard deviation $(n=3)$. Comparison among treatment group was carried out via Student's unpaired $t$-test $\left({ }^{*} \mathrm{p}<0.05,{ }^{*} \mathrm{p}<0.01\right)$. All of the statistical plots were plotted using Origin Software (OrginLab, USA).

\section{Results and discussion}

\subsection{Morphology of electrospun nanofibers}

The CO-ES process involves the main interaction between electrical field, solution surface tension and gravity (Gao et al., 2016). Polymer concentration is a crucial parameter which will determine the spinnability of the solution and the stability of ES process, respectively ( $\mathrm{Li}$ and Wang, 2013). In this study, the blended fibers were prepared according to compositions shown in Table 1 and the effect of CS concentration (varied from 0- $8 \mathrm{wt} \%$ ) on fibers' morphology was explored. As shown in Fig. 1b, a stable typical Taylor-cone was observed at the optimum electrical potential $(\sim 17.5 \mathrm{kV}$, vi), which evolved from dripping mode (Fig. 1bi) at $0 \mathrm{kV}$ to stretched mode at the 
voltage range from $5 \mathrm{kV}$ (Fig. 1bii) to $10.5 \mathrm{kV}$ (Fig. 1biii), then to jetting mode in the range between 13.5 (Fig. 1iv) and $15.5 \mathrm{kV}$ (Fig. 1v). The effect of CS concentration on fiber formation is shown in Fig. 2. The OM images (Fig. 2a1-e1) show ultrafine fibers obtained from polymer solutions with various CS concentrations, suggesting increasing the CS concentration results in more uniform fibers. Fig. 2a2-e2 show the SEM images and their high magnification of the engineered fibers with various morphology as a result of CS concentration. Bifurcate and sticking together fibers (Fig. 2a2 (F-1)) at low CS concentration were more obvious than other images (Fig. 2 b2-e2), and the more "embossments" showed in the inset images as the increasing of CS concentration.

The improvement of fiber surface morphology by using CS may be attributed to the fact that CS possesses a cationic polyelectrolytic property in acidic media; increasing the surface charges concentration of the jets (Sedghi and Shaabani, 2016). A stronger elongation force is then exerted on the ejecting jets during the electrospinning process resulting in smaller, thinner fibers. The effects of CS concentration on diameter of resulting fibers were evident. The distribution of diameter was more concentrated as the increasing of CS concentration. The mean diameter of F-5 decreased from $1594 \pm$ $946 \mathrm{~nm}$ to $769 \pm 398 \mathrm{~nm}$ when increasing the CS concentration from $0 \mathrm{wt} \%$ to $8 \mathrm{wt} \%$. In order to confirm the core-shell structure (F-5), following in vitro release studies the fibers were analyzed using SEM. Fig. $2 \mathrm{f} 1$ and $\mathrm{f} 2$ confirm the inner structure (PVP-5FU) has dissolved, resulting in hollow fibrous structures. Moreover, some fibers possessed several hollowed sections (Fig. 2f1, labeled with green arrow) which may be due to the synergistic effects of phase segregation and disturbance of roller during $\mathrm{CO}$ ES process.

\subsection{FT-IR analysis of core-shell nanofibers}

FT-IR spectra of CS, 5-FU, and resulting fibers are shown in Fig. 3a. The peaks at around 2949 and $1729 \mathrm{~cm}^{-1}$ was the vibration of $\mathrm{C}=\mathrm{O}$ and $\mathrm{CH}_{2}$ respectively, in PCL (Wang et al., 2016); with the $\mathrm{CH}_{2}$ twisting, $\mathrm{C}=\mathrm{O}$ vibration, $\mathrm{CH}_{2}$ stretching being responsible for the absorption peaks appearing at 1288, 1654, and $2954 \mathrm{~cm}^{-1}$, respectively (Wu et al., 2018). Characteristic peaks of CS can be seen at $872 \mathrm{~cm}^{-1}$ and 
broad peaks arising at $3423 \mathrm{~cm}^{-1}$ region are due to $\beta-(1,4)$ glycosidic vibrations of $\mathrm{O}$ $\mathrm{H}$ and N-H, respectively (Yue et al., 2009). The peaks showed at $1556 \mathrm{~cm}^{-1}$ and 1656 $\mathrm{cm}^{-1}$ region were the vibration of amide II band and amide I band respectively (Kucukgulmez et al., 2011; Rinaudo, 2006) and the hydrogen bond between N-H and $\mathrm{C}=\mathrm{O}$ group was highlighted at $1656 \mathrm{~cm}^{-1}$ (Kucukgulmez et al., 2011).

The absorption peaks around 3067,2939 and $2828 \mathrm{~cm}^{-1}$ in the spectra of pure $5-\mathrm{FU}$ are attributed to aromatic and aliphatic C-H vibration (Kevadiya et al., 2012); and the CO-NH-CO, amide I and amide III $(\mathrm{C}=\mathrm{O})$ peaks found at 1725, 1672, and $1247 \mathrm{~cm}^{-1}$, respectively (Lin et al., 2002). The vibration of C-H located in-plane and out-of-plane of $\mathrm{CF}=\mathrm{CH}$ showed peaks at 1426 and $814 \mathrm{~cm}^{-1}$, respectively (Kevadiya et al., 2012). When comparing the spectra of resulting fibers loaded with 5-FU and CS of various concentration, these characteristic peaks of CS and 5-FU can be seen in all cases with slight shifts in wavelength, indicating CS and 5-FU were not only attached on the surface but also existed within the fibers by the formation of chemical bonds (i.e. hydrogen bonds) (Nazari et al., 2017).

\subsection{XRD analysis of core-shell nanofibers}

The powder XRD analysis was used to reveal the changes in physical state of drugs and fibers during CO-ES process. As shown in Fig. 3b, the pristine PCL, the sharp diffraction peak at $2 \theta=22.2^{\circ}$ was attributed to the diffraction of lattice plane (200) (Meng et al., 2010). The XRD spectrum of PVP showed two broad diffraction peaks at $2 \theta=11.3^{\circ}, 21.0^{\circ}$, indicating amorphous PVP was helpful for drug delivery (Wu et al., 2018). In the spectrum of 5-FU powder, the diffraction peaks at $2 \theta=16.1^{\circ}$, $18.8^{\circ}, 19.9^{\circ}, 21.7^{\circ}, 28.4^{\circ}, 31.9^{\circ}$, and $33.0^{\circ}$ are consistent with the results showed in previous work ( $\mathrm{Li}$ et al., 2011); and demonstrate the 5-FU powder existed in the crystalline state. The diffraction peaks of CS appeared at $2 \theta=6.2^{\circ}, 10.2^{\circ}, 20.1^{\circ}, 30.1^{\circ}$, $35.2^{\circ}, 38.0^{\circ}$; and the peak at $2 \theta=20.1^{\circ}$ was due to diffraction of plane $(020,110)$ (Lavall et al., 2007).

The diffraction peaks for PCL/PVP appeared at $2 \theta=21.1^{\circ}, 24.1^{\circ}$. While comparing with the pure PCL powder, the intensity of the diffraction peaks for PCL/PVP blending 
fibers had decreased, which may be attributed to the slowed crystallization of PCL during CO-ES process (Meng et al., 2010). Besides, the differences between the XRD spectrum between PCL-CS/PVP-5-FU and PCL/PVP were obvious: two sharp diffraction peaks overlaid with a broad peak appeared at $2 \theta=20.9^{\circ}, 24.0^{\circ}$. This probably resulted from the vibration of CS attached on the PCL surface, and demonstrating the content of CS and 5-FU can influence the crystallization and crystal type of PCL-CS/PVP-5-FU blending fibers.

\subsection{Surface hydrophilicity}

The hydrophilicity of film influences drug release and is crucial for bio-related applications (Wang et al., 2018). Here, water contact angle (CA) of resulting fibers was measured to reveal the effects of CS or 5-FU concentration on fibrous hydrophilicity. The results are shown in Fig. 4. The initial CA $(\theta$, the CA at the moment that water drop contacts fibers surface) of F-1, F-2, F-3, F-4, and F-5 films were 114.4, 90.1, 84.2, 73.1, and $71.8^{\circ}$, respectively. The results indicate F-1 and F-2 films are hydrophobic, while the F-3, F-4 and F-5 films were hydrophilic. The increase in CS concentration in PCL improved hydrophilicity of the films. Moreover, the CA value $(\theta)$ of the electrospun films was examined over a period of $240 \mathrm{~s}$ as shown in Fig. 4b. The final CA of F-1, F2, F-3, F-4, and F-5 films were 101.4, 61.1, 18.6, 0, and $0^{\circ}$, respectively. As shown in Fig. S2, the change of CA over time was not constant, a steep decline followed slowly decreasing. The final CA decreased to $0^{\circ}$ in $8 \mathrm{~s}$ for F-4, and $3 \mathrm{~s}$ for F-5. The results the more CS there is present in the fibers, the fast the diffusion of water through the fibers. This may be due to that the surface morphology of fiber was rougher when the content of CS was higher (shown with the SEM images in Fig. 2). As CS concentration increased, the gap between two fibers increased which was conducive to flow of medium. Therefore, addition with CS can broaden the application of hydrophobic agents.

\subsection{Mechanical properties}

Under tensile stress, the film was stretched and elongated as shown in Fig. 5a. Once 
a specified distance between two clampers for test sample is reached, tensile stress can be recorded at various stages (Fig. S3). Fig. 5b shows tensile curves for different samples and reveals each sample possessed ductile failure characteristics (Shi et al., 2018). The maximum tensile strain decreased as the CS content increased; decreasing from $332 \%$ for F-1 to $33.7 \%$ for F-5. Besides, the maximum tensile stress decreased with increase of CS content, except for F-3 composite films. The maximum tensile stresses of simple F-1 and F-5 composite films were $33.2 \mathrm{MPa}$ and 4.8 $\mathrm{MPa}$, respectively. The addition of ingredients content minimized the mechanical properties of composite films, which is consistent with the results showed in previous work (Wang et al., 2016). This is attributed to the changes of composite films microstructure resulting from addition of CS and 5-FU. When PCL/PVP composite fiber encapsulated $\mathrm{CS}$ and 5-FU, the polymer matrix molecular chains were likely to be discontinuous and uneven; resulting in rough surfaces (see Fig. 2 SEM images). Enlarging the gap between fibers would result in low tensile strength. However, the membranes presented good mechanical property without rupturing.

\subsection{In-vitro release of $\mathrm{CS}$ and 5-FU}

The CO-ES process has showed effective and economic superiority for loading capacity (LC) and encapsulation efficiency (EE) of ingredients (Wang et al., 2018). Here, the effect of CS content on the LC and EE was examined. When CS content increased from $2 \mathrm{wt} \%$ to $8 \mathrm{wt} \%$, LC of 5 -FU ranged from $0.43 \pm 0.01 \%$ to $0.48 \pm 0.02 \%$, and $\mathrm{EE}$ of 5-FU increased from $87.7 \pm 3.1 \%$ to $97.7 \pm 3.4 \%$ (Fig. 6a). The influence of CS content on the LC and EE was not obvious, which due to the 5-FU content was constant $(2 \mathrm{wt} \%)$ and was encapsulated in core layer. However, higher content of CS improved LC and EE. The LC increased from $3.19 \pm 0.14 \%$ to $14.1 \pm 0.66 \%$, while EE was in the range of $90.4 \pm 0.4 \%$ and $94 \pm 0.7 \%$, when CS content was increased from $2 \mathrm{wt} \%$ to $8 \mathrm{wt} \%$, as shown in Fig. 6 b.

To mimic the general micro-environment of melanoma cells, the releases of composite films were performed in PBS ( $\mathrm{pH}=5.7 \pm 0.1$ ) (Sahu et al., 2017; Wang et al., 2018). As results show in Fig. S4a \& b, nearly $60 \%$ and $89 \%$ of CS and 5-FU was 
released within the first $10 \mathrm{~h}$, respectively. The higher content of CS improved the release of CS and 5-FU, except for the release of CS and 5-FU from F-3 films. The rapid dissolution of the PVP core layer resulted in the "burst" release of 5-FU. The rapid release of $\mathrm{CS}$ was due to the faintly acid micro-environment $(\mathrm{pH}=5.7 \pm 0.1)$ which improves the solubility of CS (Pillai et al., 2009). Moreover, CS was loaded in outer shell layer, thus the difference between the cumulative release of CS and 5-FU was less significant than in theory.

In vitro results of drug release indicate that $\sim 78 \%$ of CS and $91 \%$ of 5 -FU were released within $24 \mathrm{~h}$, respectively (Fig. 6c). The burst release characteristic of 5-FU and sustained release of CS was revealed within the first 120 min (Fig. 6d). Nearly $87 \%$ of 5-FU was released from F-5 and approximate 40\% of CS was released within $120 \mathrm{~min}$. This offers a desirable anticancer property with minimum adverse effects. In addition, to quantify the $\mathrm{CS} / 5-\mathrm{FU}$ release mechanisms, the in-vitro release data was fitted to Korsmeyer-Peppas model and first order model (Dash et al., 2010). As seen in Table 2, both high correlation coefficients $\left(R^{2}\right)$ were obtained from the Korsmeyer-Peppas model (Fig. S4 c-f). The $n$ value for CS and 5-FU was 0.3881 and 0.2489 , respectively. This indicates the release of CS and 5-FU were dominated mainly by Fickian diffusion mainly $(n<0.45)$.

\subsection{Evaluation of anticancer effect}

The effect of 5-FU on L929 (fibroblast cell) and B16F10 (mouse melanoma cell) proliferation were assessed using CCK-8 method. As shown in Fig. 7 a \& b, the cell viability of L929 and B16F10 were significantly decreased upon 5-FU treatment in a dose-dependent manner. This confirmed the inhibitory effects of 5-FU on melanoma cells (B16F10 cells) and unavoidable negative effect on normal skin cells (L929 cells). Thus, restoring efficacy by using CS to compensate the adverse effects of 5-FU on normal cells is needed in practice. Compared to the 5-FU treatment group, the decrease of cell viability for negative group (DMSO) was less obvious, which indicates the sideeffect of solvent (DMSO) was negligible and the inhibitory effect resulted mainly from 5-FU. 


\subsubsection{Anticancer effect on melanoma cell (B16F10)}

The ability of the engineered films to induce apoptosis in B16F10 cells was investigated using flow cytometry analysis. As shown in Fig. 8a, b1\&b2, the proportion of early apoptosis stage cells (quadrant 4th: lower right) and late apoptosis stage cells (quadrant 1st: upper right) evidently increased upon treatment of F-5 composite sample in time-dependent manner when compared to the blank control group (Fig. 8a). The proportion of quadrant 1 cells increased from $0.8 \%$ (Fig. S5a i) to $20.7 \%$ and $62.2 \%$ after being treatment for $8 \mathrm{~h}$ (Fig. S5a ii) and $24 \mathrm{~h}$ (Fig. S5a iii), respectively. The proportion of quadrant 4 cells increased from $0.1 \%$ (Fig. S5a i) to $14.5 \%$ and $12.8 \%$ after being treatment $8 \mathrm{~h}$ (Fig. S5a ii) and $24 \mathrm{~h}$ (Fig. S5a iii), respectively. These results indicate that the F-5 composite sample inhibited the proliferation of B16F10 cells and induced apoptosis in a time-dependent manner.

The effects of F-5 films on cell cycle of B16F10 was determined using flow cytometry analysis (Fig. 8a', b1'\& b2'). As shown in Fig. 8c, the ratio of B16F10 cells in G0/G1 phase decreased slightly upon treatment with F-5 composite films $(64.8 \pm 0.7 \%$ for $8 \mathrm{~h}$, and $64.4 \pm 0.5 \%$ for $24 \mathrm{~h})$ comparing with blank control $(65.8 \pm 1.4 \%)$. The proportion of cells in S and G2/M phases were influenced by blending films obviously. The proportion of cells in S and G2/M phases for control group was $20.6 \pm 0.3 \%$ and $7.9 \pm 1.0 \%$, respectively. After being treated for $8 \mathrm{~h}$, the proportion of cells in the two phases was $22.1 \pm 0.3 \%$ and $5.4 \pm 0.4 \%$, respectively. When the treatment time prolong to $24 \mathrm{~h}$, the proportion of cells in the two phases was $14.5 \pm 1.5 \%$ and $12.1 \pm 1.6 \%$, respectively.

\subsubsection{Synergetic effect on fibroblast cell (L929 cell)}

For the L929 cells, the proportion of quadrant 3rd cells (vital cells) (lower left quadrant) for treatment groups (Fig. 9b1-c2) were smaller than that of blank control group (Fig. 8a), which demonstrates the adverse effect of 5-FU treatment on L929 cells (normal skin cells). The pie chart results (Fig. S5b) offered precise results with the vital cells of treatment groups being smaller than that of blank control group $(82.47 \%)$. 
Moreover, the difference between the treatment of blending fibrous film without CS (Fig. $8 \mathrm{~b} 1 \& \mathrm{c} 1$ ) and with CS (Fig. $8 \mathrm{~b} 2 \& \mathrm{c} 2$ ) were significant. The proportion of quadrants 1 st, $3 \mathrm{rd}$, and 4 th cells number were evidently influenced by the CS. As shown in the pie chart, the proportion of quadrant $3 \mathrm{rd}$ cells increased from $47.95 \%$ to $78.83 \%$, after being treated with F-0 (Fig. S6b ii) and F-5 (Fig. S6b iii) blending films for 8 h. The early apoptosis stage cells decreased from $22.67 \%$ to $8.85 \%$. These results show CS can enhance the vital cells number and reduce apoptosis cells number. These results confirmed the "remedying" effects of CS on L929 cells suffered adverse effects from 5-FU by accident.

Fig. 8b1' to c2' show that the ratio of L929 cells in G0/G1 and S phases was influenced by the blended films; both with and without CS. For the control group, the ratio of L929 cells in G0/G1 and S phases was $73.39 \pm 0.61 \%$ and $10.77 \pm 0.33 \%$, respectively. After being treatment for $8 \mathrm{~h}$, the ratio of cells in G0/G1 and S phases was $52.23 \pm 1.42 \%$ and $37.47 \pm 0.85 \%$ for the F-5 films, and $70.3 \pm 1.1 \%$ and $17.54 \pm 0.65 \%$ for the F-0 films. The effects of decreased cells proportion in G0/G1 and increased cells proportion in S phase effects were also revealed CS following $24 \mathrm{~h}$ of treatment with films with and without CS.

\section{8. $\mathrm{AO} / \mathrm{EB}$ staining}

$\mathrm{AO} / \mathrm{EB}$ dual fluorescent staining was used to visualize the inhibitory effect and "remedying" effect of F-5 composite films on B16F10 and L929 cells, respectively. As the results show in Fig. 10, the cells were divided into four types using these two DNA dyes, where vital cells (green), early apoptosis cells (green with orange spots), late apoptosis cells (green with orange area), necrotic cells (red) (Kamel et al., 2017). As shown in Fig. 10a \& b, all the cells exhibited green fluorescence, which indicates the PCL/PVP blending films (Fig. 10b) do not have side-effects on B16F10 cells (Fig. 10a). The proportion of apoptosis and necrotic cells in treatment groups (Fig. 10c1-c2) were varied when compared to the control (Fig. 10a), demonstrating the anticancer effects of 5-FU loaded blending films against B16F10 cells.

Meanwhile, the proportion of apoptosis and necrotic cells following treatment with 
CS and 5-FU loaded blending films (Fig. 10c2) were less than that for blending films loaded with 5-FU only (Fig. 10c1), which may be attributed to the proliferation promotion nature of CS (Zhu et al., 2019). For the L929 cells, the green fluorescence with the control (Fig. 10a') and negative control (Fig. 10b') do not show any obvious differences, which indicates the PCL/PVP blending films do not have side-effects on L929 cells. Moreover, the proportion of apoptosis and necrotic cells in treatment of blending films encapsulating 5-FU only for $8 \mathrm{~h}$ (Fig. S8a) were decreased in the treatment of films encapsulating CS and 5-FU at the same time (Fig. S8b). These results confirmed the "remedying" effects of CS on L929 cells suffered adverse effects from 5-FU by accident. Thus, the "remedying" effects of composite films on L929 cells were confirmed, and may be obtained from "rescuing" early apoptosis cells.

\section{Conclusion}

In this work, a novel core-shell nanofiber drug delivery system for skin melanoma was investigated. Core-shell structure PCL/PVP composite nanofiber loading CS (chitosan) and 5-FU (5-Fluorouracial) into shell layer and core layer, respectively. The PCL-CS/PVP-5-FU fibers had an average diameter of $\sim 503 \mathrm{~nm}$ and presented high drug-encapsulating efficiency, and good mechanical properties. Moreover, the proposed films showed significant inhibitory proliferation effects on B16F10 cells invitro through arresting cell cycle progression at $\mathrm{S}$ phase and $\mathrm{G} 2 / \mathrm{M}$ phase in timedependent manner. More importantly, the composite films possessed the "remedying" ability to compensate the adverse effect of L929 cells suffered from 5-FU may through increasing cell cycle progression at G0/G1 phase and S phase mainly. It is expected that an effective therapeutic for melanoma possessing minimum adverse effects of 5-FU on normal cells will be realized in future clinical trials in this way.

\section{Declaration of interest}

There are no conflicts to declare.

\section{Acknowledgements}


This work was financially supported by the National Nature Science Foundation of China (No. 81771960), the Fundamental Research Funds for the Central Universities (2017QNA5017) and Key Technologies R\&D Program of Zhejiang Province (2015C02035). 


\section{References}

Ali, H., Shirode, A.B., Sylvester, P.W., Nazzal, S., 2010. Preparation, characterization, and anticancer effects of simvastatin-tocotrienol lipid nanoparticles. Int. J. Pharm. 389, 223231.http://doi.org/10.1016/j.jpharm.2010.01.018

Chen, G., Fang, D., Wang, K., Nie, J., Ma, G., 2015. Core-shell structure PEO/CS nanofibers based on electric field induced phase separation via electrospinning and its application. J. Polym. Sci,. Part. A:. Polym. Chem. 53, 2298-2311.http://doi.org/10.1002/pola.27702

Cho, Y.W., Jang, J., Park, C.R., Ko, S.W., 2000. Preparation and solubility in acid and water of partially deacetylated chitins. Biomacromolecule. 1, 609-614.http://doi.org/10.1021/bm000036j

Dash, S., Murthy, P.N., Nath, L., Chowdhury, P., 2010. Kinetic modeling on drug release from controlled drug delivery systems. Acta. Pol. Pharm. 67, 217 223.http://doi.org/:10.1038/aps.2010.43

Dev, A., Binulal, N.S., Anitha, A., Nair, S.V., Furuike, T., Tamura, H., Jayakumar, R., 2010. Preparation of poly(lactic acid)/chitosan nanoparticles for anti-HIV drug delivery applications. Carbohyd. Polym. 80, 833-838.http://doi.org/10.1016/j.carbpol.2009.12.040

Esteva, A., Kuprel, B., Novoa, R.A., Ko, J., Swetter, S.M., Blau, H.M., Thrun, S., 2017. Dermatologistlevel classification of skin cancer with deep neural networks. Nature. 542, 115.http://doi.org/10.1038/nature21056

Forward, K.M., Flores, A., Rutledge, G.C., 2013. Production of core/shell fibers by electrospinning from a free surface. Chem. Eng. Sci. 104, 250-259.https://doi.org/10.1016/j.ces.2013.09.002

Gao, Y., Zhao, D., Chang, M.-W., Ahmad, Z., Li, J.-S., 2016. Optimising the shell thickness-to-radius ratio for the fabrication of oil-encapsulated polymeric microspheres. Chem. Eng. J. 284, 963971.https://doi.org/10.1016/j.cej.2015.09.054

García Cruz, D.M., Coutinho, D.F., Mano, J.F., Gómez Ribelles, J.L., Salmerón Sánchez, M., 2009. Physical interactions in macroporous scaffolds based on poly( $\varepsilon$-caprolactone)/chitosan semiinterpenetrating polymer networks. Polymer. 50, 20582064.https://doi.org/10.1016/j.polymer.2009.02.046

Gray-Schopfer, V., Wellbrock, C., Marais, R., 2007. Melanoma biology and new target therapy. Nature. 445, 851-857.http://doi.org/10.1038/nature05661

Jia, D., Gao, Y., Williams, G.R., 2017. Core/shell Eudragit/poly(ethylene oxide) fibers for site-specific release. Int. J. Pharm. 523, 376.http://doi.org/10.1016/j.jpharm.2017.03.038

Kamel, K.M., Khalil, I.A., Rateb, M.E., Elgendy, H., Elhawary, S., 2017. Chitosan-Coated Cinnamon/Oregano-Loaded Solid Lipid Nanoparticles to Augment 5-Fluorouracil Cytotoxicity for Colorectal Cancer: Extract Standardization, Nanoparticle Optimization, and Cytotoxicity Evaluation. 
J. Agric. Food. Chem. 65, 7966-7981.http://doi.org/jafc.7b03093

Kevadiya, B.D., Patel, T.A., Jhala, D.D., Thumbar, R.P., Brahmbhatt, H., Pandya, M.P., Rajkumar, S., Jena, P.K., Joshi, G.V., Gadhia, P.K., Tripathi, C.B., Bajaj, H.C., 2012. Layered inorganic nanocomposites: A promising carrier for 5-fluorouracil (5-FU). Eur. J. Pharm. Biopharm. 81, 91101.https://doi.org/10.1016/j.ejpb.2012.01.004

Khan, M.A., Pandit, J., Sultana, Y., Sultana, S., Ali, A., Aqil, M., Chauhan, M., 2015. Novel carbopolbased transfersomal gel of 5 -fluorouracil for skin cancer treatment: in vitro characterization and in vivo study. Drug. Deliv. 22, 795-802.http://doi.org/10.3109/10717544.2014.902146

Kim, G.M., Le, K.H., Giannitelli, S.M., Lee, Y.J., Rainer, A., Trombetta, M., 2013. Electrospinning of PCL/PVP blends for tissue engineering scaffolds. J. Mater. Sci. Mater. Med. 24, 14251442.http://doi.org/10.1007/s10856-013-4893-6

Kucukgulmez, A., Celik, M., Yanar, Y., Sen, D., Polat, H., Kadak, A.E., 2011. Physicochemical characterization of chitosan extracted from Metapenaeus stebbingi shells. Food. Chem. 126, 1144 1148.http://doi.org/10.1016/j.foodchem.2010.11.148

Kurita, K., 2006. Chitin and chitosan: functional biopolymers from marine crustaceans. Mar. Biotechnol. 8, 203.http://doi.org/10.1007/s10126-005-0097-5

Lavall, R.L., Assis, O.B., Campanafilho, S.P., 2007. Beta-chitin from the pens of Loligo sp.: extraction and characterization. Bioresource Technol. 98, 2465.http://doi.org/10.1016/j.biortech.2006.09.002 Lee, H., Lee, J.H., Kim, J., Mun, J.H., Chung, J., Koo, H., Kim, C., Yun, S.H., Hahn, S.K., 2016. Hyaluronate-Gold Nanorod/DR5 Antibody Complex for Noninvasive Theranosis of Skin Cancer. ACS Applied Materials \& Interfaces 8, 32202-32210.http://doi.org/10.1021/acsami.6b11319

Li, P., Wang, Y., Peng, Z., She, F., Kong, L., 2011. Development of chitosan nanoparticles as drug delivery systems for 5-fluorouracil and leucovorin blends. Carbohydr. Polym. 85, 698704.https://doi.org/10.1016/j.carbpol.2011.03.045

Li, Z., Wang, C., 2013. Effects of Working Parameters on Electrospinning, in: Li, Z., Wang, C. (Eds.), One-Dimensional nanostructures: Electrospinning Technique and Unique Nanofibers. Springer Berlin Heidelberg, Berlin, Heidelberg, pp. 15-28.https://doi.org/10.1007/978-3-642-36427-3_2 Lin, F.H., Lee, Y.H., Jian, C.H., Wong, J.-M., Shieh, M.-J., Wang, C.-Y., 2002. A study of purified montmorillonite intercalated with 5-fluorouracil as drug carrier. Biomaterials. 23, 19811987.https://doi.org/10.1016/S0142-9612(01)00325-8

Liu, D., Wei, Y., Yao, P., Jiang, L., 2006. Determination of the degree of acetylation of chitosan by UV spectrophotometry using dual standards. Carbohydr. Res. 341, 782785.https://doi.org/10.1016/j.carres.2006.01.008

Longley, D.B., Harkin, D.P., Johnston, P.G., 2003. 5-Fluorouracil: mechanisms of action and clinical strategies. Nature Reviews Cancer 3, 330.http://doi.org/10.1038/nrc1074 
Ma, Y.S., Hsiao, Y.T., Lin, J.J., Liao, C.L., Lin, C.C., Chung, J.G., 2017. Phenethyl Isothiocyanate (PEITC) and Benzyl Isothiocyanate (BITC) Inhibit Human Melanoma A375.S2 Cell Migration and Invasion by Affecting MAPK Signaling Pathway In Vitro. Anticancer. Res. 37, 62236234.http://doi.org/10.21873/anticanres.12073

Meng, Z.X., Zheng, W., Li, L., Zheng, Y.F., 2010. Fabrication and characterization of threedimensional nanofiber membrance of PCL-MWCNTs by electrospinning. Mater. Sci. Eng,. C. 30, 1014-1021.http://doi.org/10.1016/j.msec.2010.05.003

Nazari, K., Kontogiannidou, E., Ahmad, R.H., Gratsani, A., Rasekh, M., Arshad, M.S., Sunar, B.S., Armitage, D., Bouropoulos, N., Chang, M.W., 2017. Development and characterisation of cellulose based electrospun mats for buccal delivery of non-steroidal anti-inflammatory drug (NSAID). Eur. J. Pharm. Sci. 102, 147-155.http://doi.org/10.1016/j.ejps.2017.02.033

Pillai, C.K.S., Paul, W., Sharma, C.P., 2009. Chitin and chitosan polymers: Chemistry, solubility and fiber formation. Prog. Polym. Sci. 34, 641-678.https://doi.org/10.1016/j.progpolymsci.2009.04.001 Prausnitz, M.R., Langer, R., 2008. Transdermal drug delivery. Nat. Biotechnol. 26, 12611268.http://doi.org/10.1038/nbt.1504

Ragetly, G.R., Griffon, D.J., Lee, H.B., Fredericks, L.P., Gordon-Evans, W., Chung, Y.S., 2010. Effect of chitosan scaffold microstructure on mesenchymal stem cell chondrogenesis. Acta. Biomater. 6, 1430-1436.http://doi.org/10.1016/j.actbio.2009.10.040

Rezaei, M., Abbasi, A., Dinarvand, R., Jedditehrani, M., Janczak, J., 2018. Design and Synthesis of a Biocompatible 1D Coordination Polymer as Anti-Breast Cancer Drug Carrier, 5-Fu: In Vitro and in Vivo Studies. ACS Applied Materials \& Interfaces, acsami.8b03111.https://doi.org/10.1021/acsami.8b03111

Rinaudo, M., 2006. Chitin and chitosan: Properties and applications. Prog. Polym. Sci. 31, 603632.https://doi.org/10.1016/j.progpolymsci.2006.06.001

Ruckh, T.T., Kumar, K., Kipper, M.J., Popat, K.C., 2010. Osteogenic differentiation of bone marrow stromal cells on poly(E-caprolactone) nanofiber scaffolds. Acta. Biomater. 6, 29492959.http://doi.org/10.1016/j.actbio.2010.02.006

Sabitha, M., Sanoj Rejinold, N., Nair, A., Lakshmanan, V.K., Nair, S.V., Jayakumar, R., 2013. Development and evaluation of 5 -fluorouracil loaded chitin nanogels for treatment of skin cancer. Carbohydr. Polym. 91, 48-57.http://doi.org/10.1016/j.carbpol.2012.07.060

Sahu, P., Kashaw, S.K., Jain, S., Sau, S., Iyer, A.K., 2017. Assessment of penetration potential of pH responsive double walled biodegradable nanogels coated with eucalyptus oil for the controlled delivery of 5-fluorouracil: In vitro and ex vivo studies. J. Control. Release. 253, 122 136.http://doi.org/10.1016/j.jconrel.2017.03.023

Sedghi, R., Shaabani, A., 2016. Electrospun biocompatible core/shell polymer-free core structure 
nanofibers with superior antimicrobial potency against multi drug resistance organisms. Polymer. 101, 151-157.http://doi.org/10.1016/j.polymer.2016.08.060

Seyednejad, H., Ji, W., Yang, F., van Nostrum, C.F., Vermonden, T., van den Beucken, J.J.J.P., Dhert, W.J.A., Hennink, W.E., Jansen, J.A., 2012. Coaxially Electrospun Scaffolds Based on HydroxylFunctionalized Poly( $\varepsilon$-caprolactone) and Loaded with VEGF for Tissue Engineering Applications. Biomacromolecules. 13, 3650-3660.http://doi.org/10.1021/bm301101r

Shah, M., Chuttani, K., Mishra, A.K., Pathak, K., 2011. Oral solid compritol 888 ATO nanosuspension of simvastatin: optimization and biodistribution studies. Drug. Dev. Ind. Pharm. 37, 526537.http://doi.org/10.3109/03639045.2010.527983

Shi, R., Bin, Y., Jian, X., 2018. Study of the structural orientation and mechanical strength of the electrospun nanofibers from polymers with different chain rigidity and geometry. Polym. Bull. 75, 947-962.https://doi.org/10.1007/s00289-017-2073-4

Sun, B., Duan, B., Yuan, X., 2006. Preparation of core/shell PVP/PLA ultrafine fibers by coaxial electrospinning. J. Appl. Polym. Sci. 102, 39-45.https://doi.org/10.1002/app.24297

Sun, Z., Zussman, E., Yarin, A.L., Wendorff, J.H., Greiner, A., 2003. Compound Core-Shell Polymer Nanofibers by Co-Electrospinning. Adv. Mater. 15, 19291932.http://doi.org/10.1002/adma.200305136

Wang, B., Ahmad, Z., Huang, J., Li, J.-S., Chang, M.-W., 2018. Development of random and ordered composite fiber hybrid technologies for controlled release functions. Chem. Eng. J. 343, 379389.https://doi.org/10.1016/j.cej.2018.03.021

Wang, B., Zheng, H., Chang, M.W., Ahmad, Z., Li, J.S., 2016. Hollow polycaprolactone composite fibers for controlled magnetic responsive antifungal drug release. Colloids. Surf. B. Biointerfaces. 145, 757-767.http://doi.org/10.1016/j.colsurfb.2016.05.092

Wang, H., Zhao, Y., Wu, Y., Hu, Y.-I., Nan, K., Nie, G., Chen, H., 2011. Enhanced anti-tumor efficacy by co-delivery of doxorubicin and paclitaxel with amphiphilic methoxy PEG-PLGA copolymer nanoparticles. Biomaterials. 32, 8281-8290.https://doi.org/10.1016/j.biomaterials.2011.07.032

Wu, S., Li, J.S., Mai, J., Chang, M.W., 2018. Three-Dimensional Electrohydrodynamic Printing and Spinning of Flexible Composite Structures for Oral Multidrug Forms. ACS Appl Mater Interfaces 10, 24876-24885.http://doi.org/10.1021/acsami.8b08880

Yao, Z.C., Jin, L.J., Ahmad, Z., Huang, J., Chang, M.W., Li, J.S., 2017. Ganoderma lucidum polysaccharide loaded sodium alginate micro-particles prepared via electrospraying in controlled deposition environments. Int. J. Pharm. 524.http://doi.org/10.1016/j.ijpharm.2017.03.064

Yu, L., Dean, K., Li, L., 2006. Polymer blends and composites from renewable resources. Prog. Polym. Sci. 31, 576-602.https://doi.org/10.1016/j.progpolymsci.2006.03.002

Yue, W., He, R., Yao, P., Wei, Y., 2009. Ultraviolet radiation-induced accelerated degradation of 
chitosan by ozone treatment. Carbohydr. Polym. 77, 639642.http://doi.org/10.1016/j.carbpol.2009.02.015

Zhou, F.-L., Hubbard, P.L., Eichhorn, S.J., Parker, G.J.M., 2012. Coaxially Electrospun AxonMimicking Fibers for Diffusion Magnetic Resonance Imaging. ACS Applied Materials \& Interfaces 4, 6311-6316.http://doi.org/10.1021/am301919s

Zhu, L.-F., Li, J.-S., Mai, J., Chang, M.-W., 2019. Ultrasound-assisted synthesis of chitosan from fungal precursors for biomedical applications. Chem. Eng. J. 357, 498507.https://doi.org/10.1016/j.cej.2018.09.183 


\section{$\underline{\text { Figure Captions }}$}

Fig. 1. Schematic diagram of coaxial-electrospinning setup (a); the effect of voltage on the forming process of continuous stable-jet mode (b), i-vi: $0-17.5 \mathrm{kV}$; and 3D structural molecule model of 5-FU (c1), PVP monomer (c2), CS (c3), and PCL monomer (c4).

Fig. 2. Optical micrographs, scanning electron micrographs, and mean diameter distribution of electrospun fibers loading various concentration of CS and 5-FU: a1-a3, F-1; b1-b3, F-2; c1-c3, F-3; d1-d3, F-4; e1-e3, F-5; f1, scanning electron micrographs of F-5 fibers following in vitro release studies, and $\mathrm{f} 2$ was the higher magnification of fiber labeled red arrow in $\mathrm{fl}$.

Fig. 3. FT-IR spectra (a), and XRD spectra (b) of blending fibers, and pristine materials: CS, 5-FU, PCL, PVP.

Fig. 4. Water contact angle images of fibrous films at various time point: $0 \mathrm{~s}$ and $240 \mathrm{~s}$ (a); the value of $\theta$ in Fig. 4 a expressed with column chart (b). ${ }^{*} p<0.05,{ }^{*} p<0.01$, N.S.: not significant, $\mathrm{n}=3$.

Fig. 5. Optical image of fibrous film (F-1) during tension testing process (a); stressstrain curves of fibrous films loading various concentration of CS and 5-FU (b).

Fig. 6. The loading capacity and encapsulate efficiency of 5-FU (a) and CS (b) of electrospun fibers: F-2, F-3, F-4, F-5 films; and accumulate release of CS and 5-FU of F-5 films in PBS ( $\mathrm{pH}=5.7 \pm 0.1$ ) within $140 \mathrm{~h}(\mathrm{c})$, and first $120 \mathrm{~min}(\mathrm{~d})$.

Fig. 7. The effects of 5-FU on cell viability of L929 cells (a) and B16F10 cells (b): 0 $\mathrm{mg} / \mathrm{mL}$, blank control; N., negative control (10 $\mu \mathrm{L}$ DMSO added into $90 \mu \mathrm{L}$ MEM).

Fig. 8. Flow cytometry analysis on apoptosis and cell cycle of B16F10 cells. a, b1, and b2 are apoptosis results of B16F10 cells treated with blank control, F-5 sample for $8 \mathrm{~h}$, and F-5 sample for $24 \mathrm{~h}$, respectively; a', b1', and b2' are cell cycle results corresponding to treatment of a, b1, b2, respectively; c: the cell cycle results of control (a'), 1 (b1'), 2 (b2') expressed as column chart.

Fig. 9. Flow cytometry analysis on apoptosis and cell cycle of L929 cell. a, b1, b2, c1, and c2: are apoptosis results of L929 cells treated with blank control, F-0 films for $8 \mathrm{~h}$, F-5 films for 8 h, F-0 for 24 h, and F-5 films for 24 h, respectively; a', b1', b2', c1 ', c2' are cell cycle results corresponding to treatment of a, b1, b2, c1, and c2, respectively; 
$\mathrm{d}$ : the cell cycle results expressed as column chart (control, 1, 2, 3, 4 corresponding to a', b1', b2', c1', c2').

Fig. 10. Fluorescent images of B16F10 and L929 cells stained with AO/EB dye: a, b, c1, c2: merging fluorescent images of B16F10 cells treated with blank control, F-1 films for $24 \mathrm{~h}, \mathrm{~F}-5$ films for $8 \mathrm{~h}$, and F-5 films for $24 \mathrm{~h}$, respectively; a', b', c1', c2': merging fluorescent images of L929 cells treated with blank control, F-1 films for $24 \mathrm{~h}$, and F0 films for $24 \mathrm{~h}, \mathrm{~F}-5$ films for $24 \mathrm{~h}$, respectively. 
$\underline{\text { Tables and Figures }}$

Table 1

The solution of CO-ES.

\begin{tabular}{ccccc}
\hline & \multicolumn{4}{c}{ Fiber composition } \\
\cline { 2 - 5 } Fiber & \multicolumn{2}{c}{ core } & \multicolumn{2}{c}{ shell } \\
\cline { 2 - 5 } & $\begin{array}{r}\text { wt } \% \text { of PVP in } \\
\text { the core }\end{array}$ & $\begin{array}{c}\text { wt } \% \text { of 5-FU in } \\
\text { the core }\end{array}$ & wt\% of PCL in & wt $\%$ of CS in the \\
\hline F-0 & 98 & 2 & 100 & shell \\
F-1 & 100 & 0 & 100 & 0 \\
F-2 & 98 & 2 & 98 & 0 \\
F-3 & 98 & 2 & 96 & 2 \\
F-4 & 98 & 2 & 94 & 6 \\
F-5 & 98 & 2 & 92 & 8 \\
\hline
\end{tabular}

Table 2

Korsmeyer-Peppas model applied to release kinetics of CS and 5-FU.

\begin{tabular}{cccccc}
\hline Films & Agent & Korsmeyer-Peppas model & $k$ & $n$ & $\mathrm{R}^{2}$ \\
\hline F-5 & CS & $\log _{10}(\mathrm{Mt} / \mathrm{M} \infty)=0.3881 \log _{10}(\mathrm{t})+1.4918$ & 6979.99 & 0.3881 & 0.9138 \\
F-5 & 5 -FU & $\log _{10}(\mathrm{Mt} / \mathrm{M} \infty)=0.2489 \log _{10}(\mathrm{t})+1.9339$ & $5.89 \times 10^{7}$ & 0.2489 & 0.9268 \\
\hline
\end{tabular}




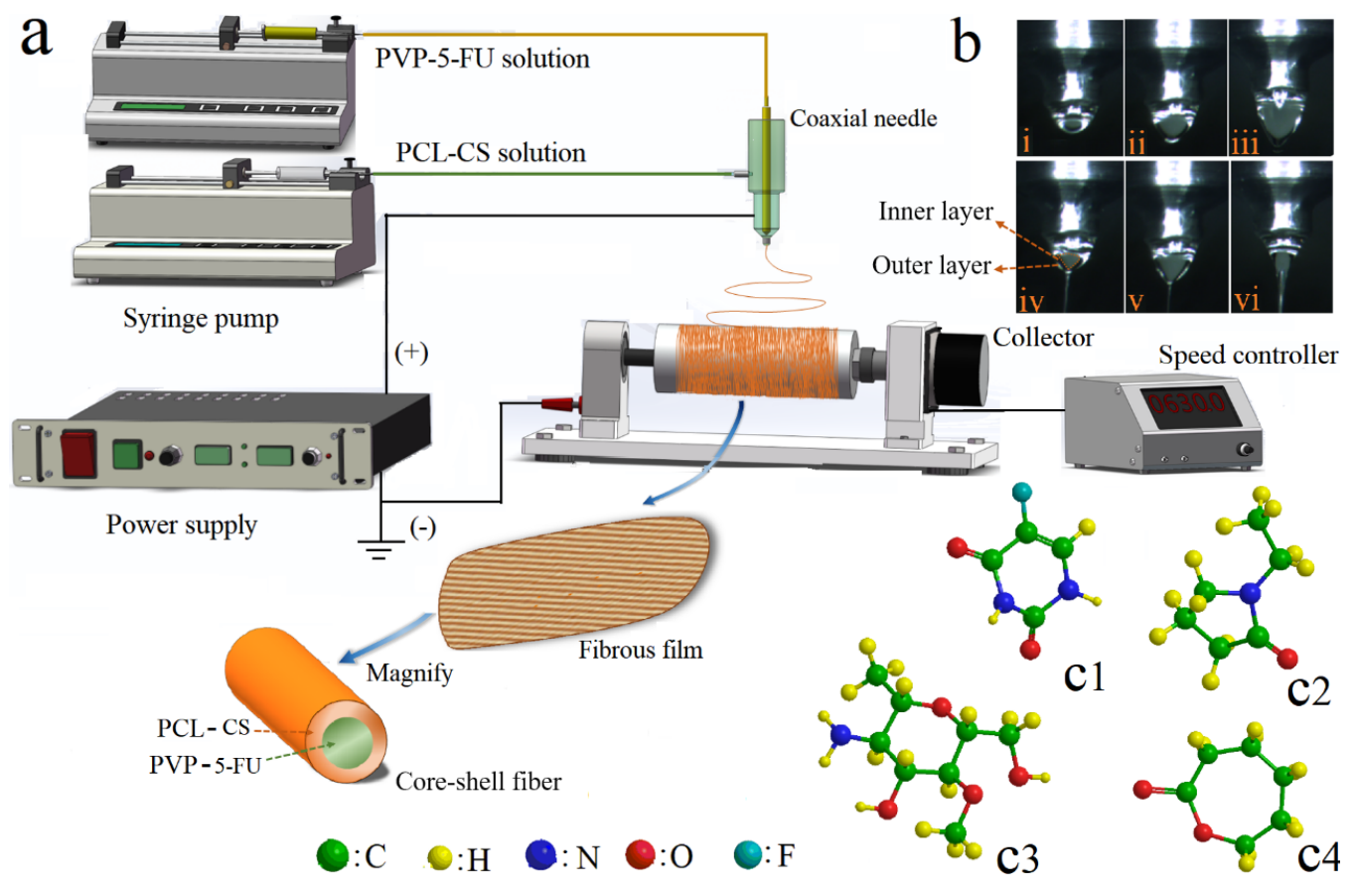

Fig. 1. 

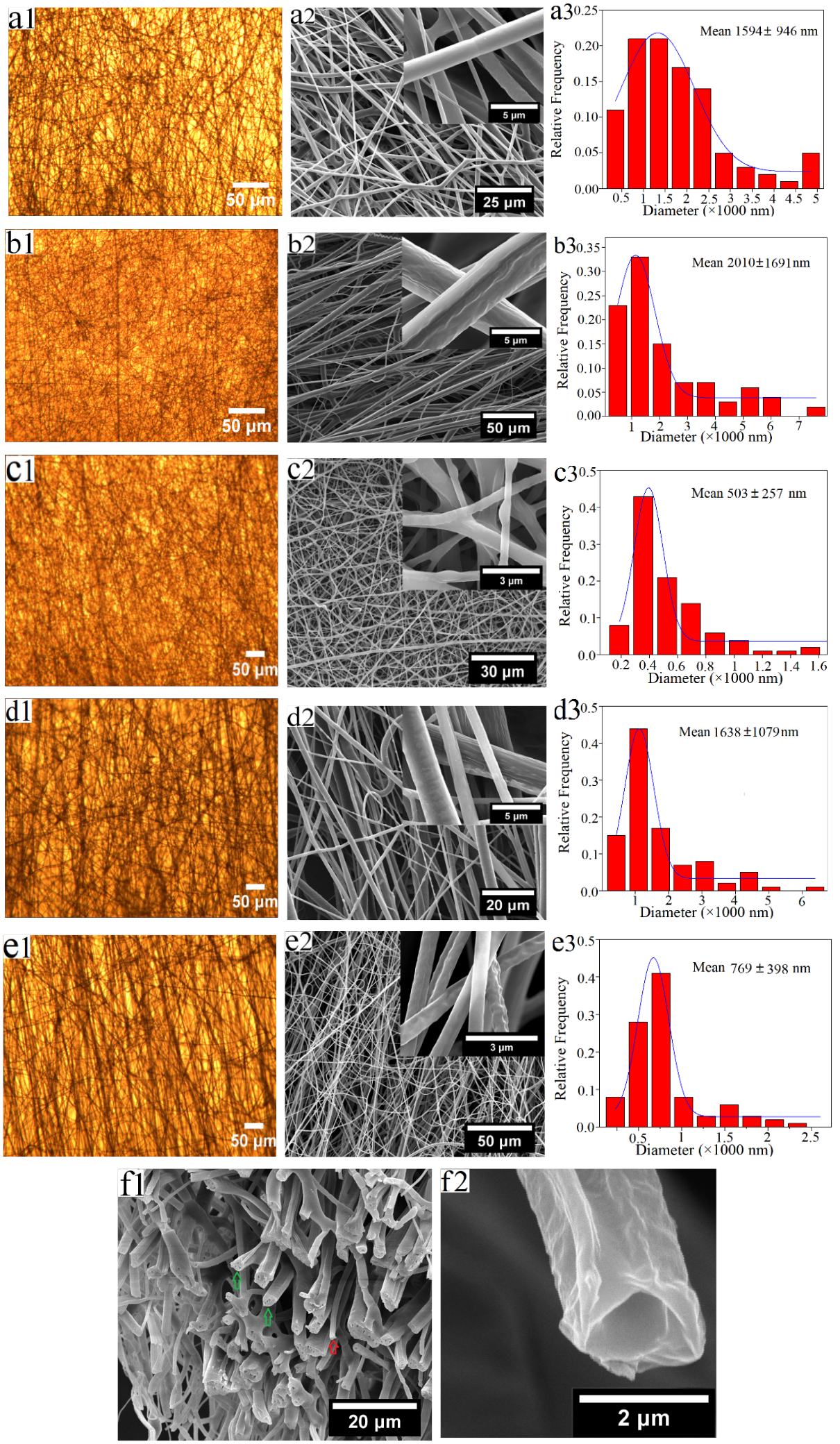

Fig. 2. 

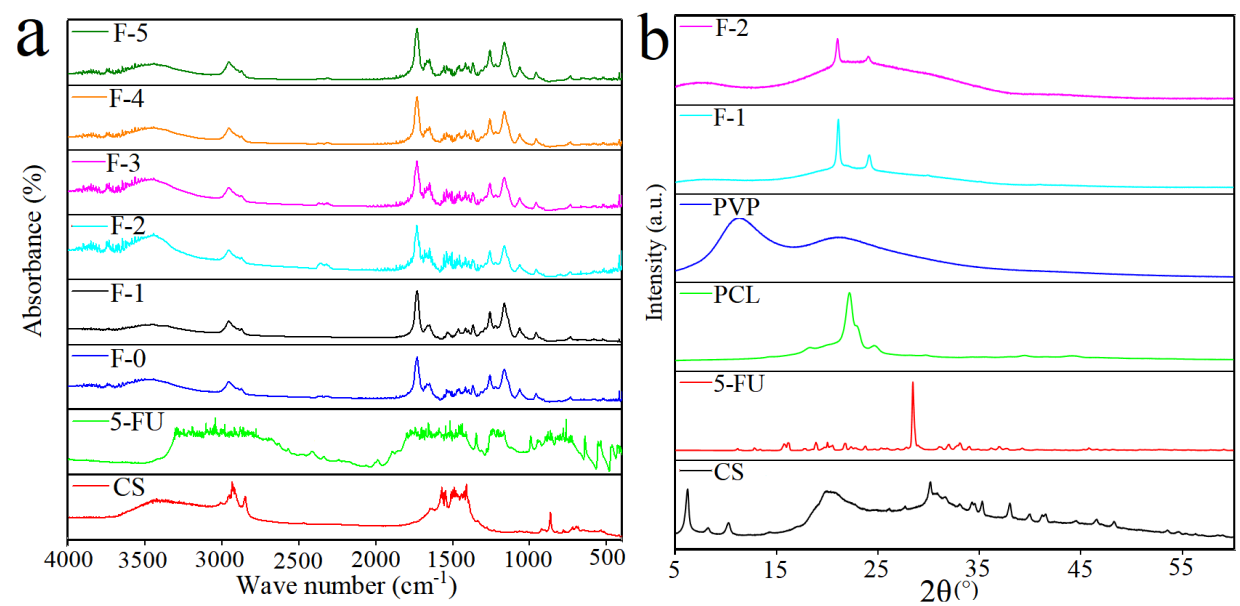

Fig. 3.
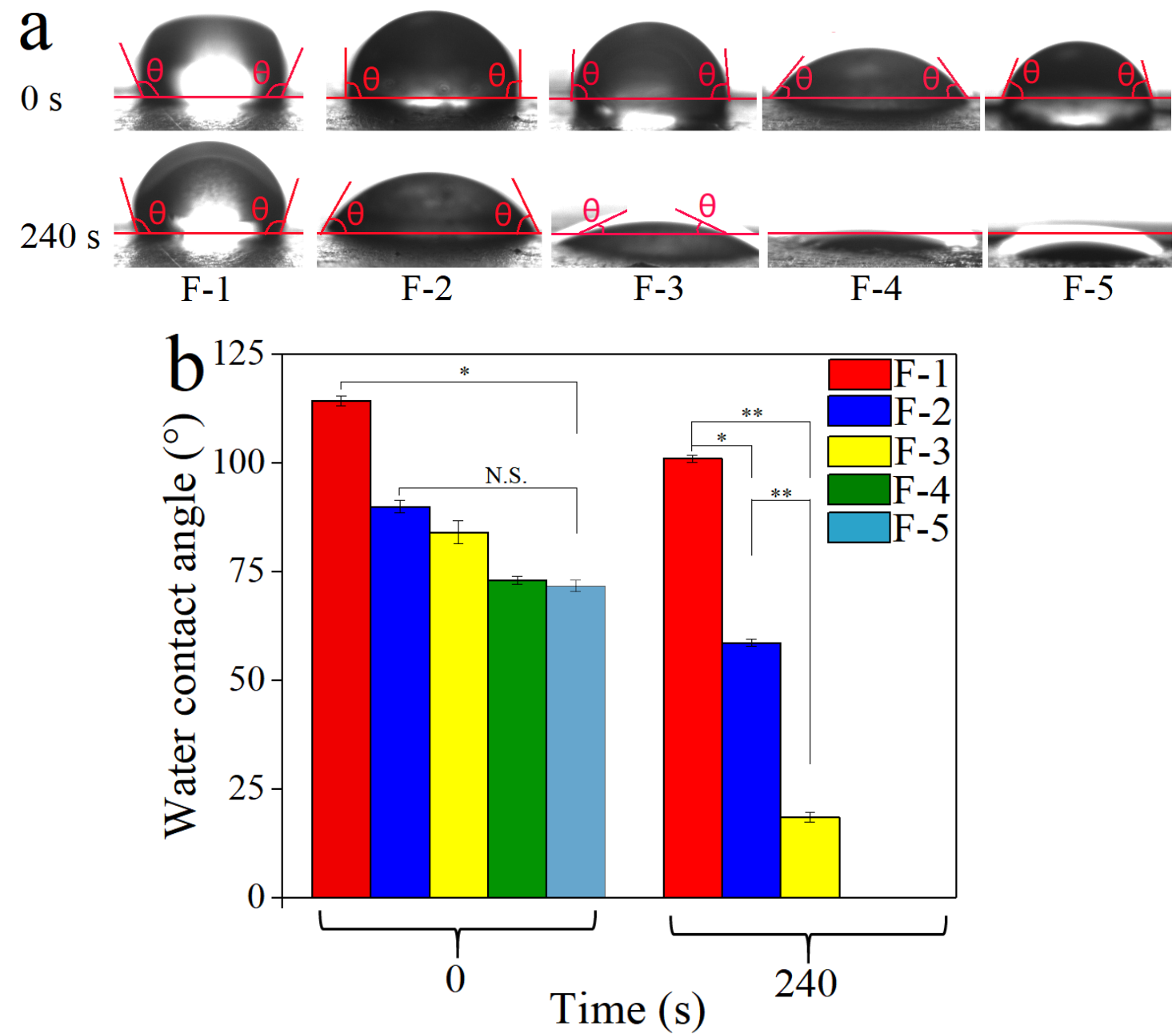

Fig. 4. 


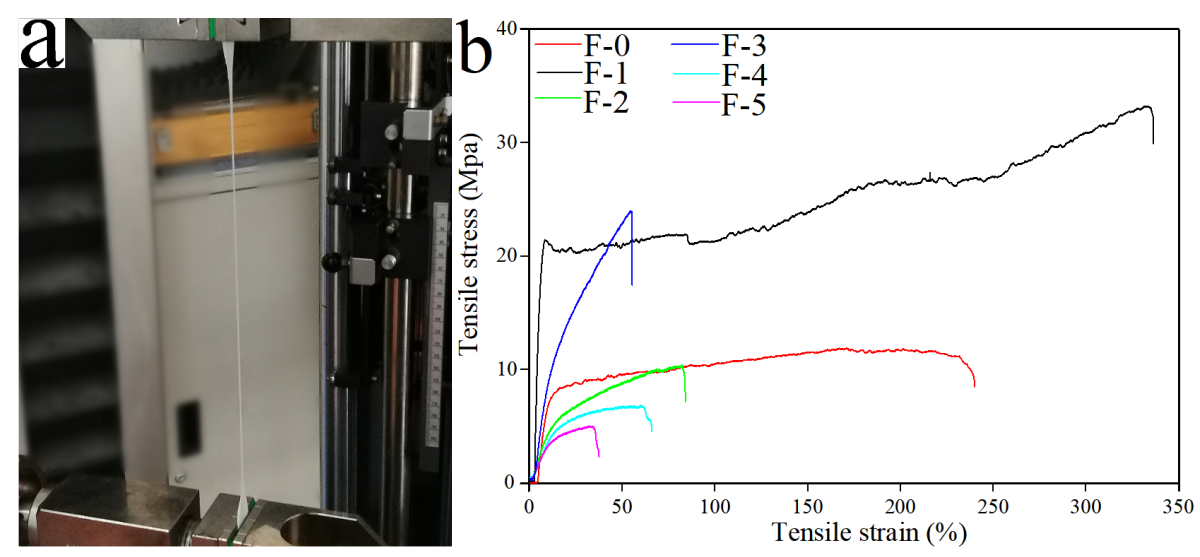

Fig. 5.
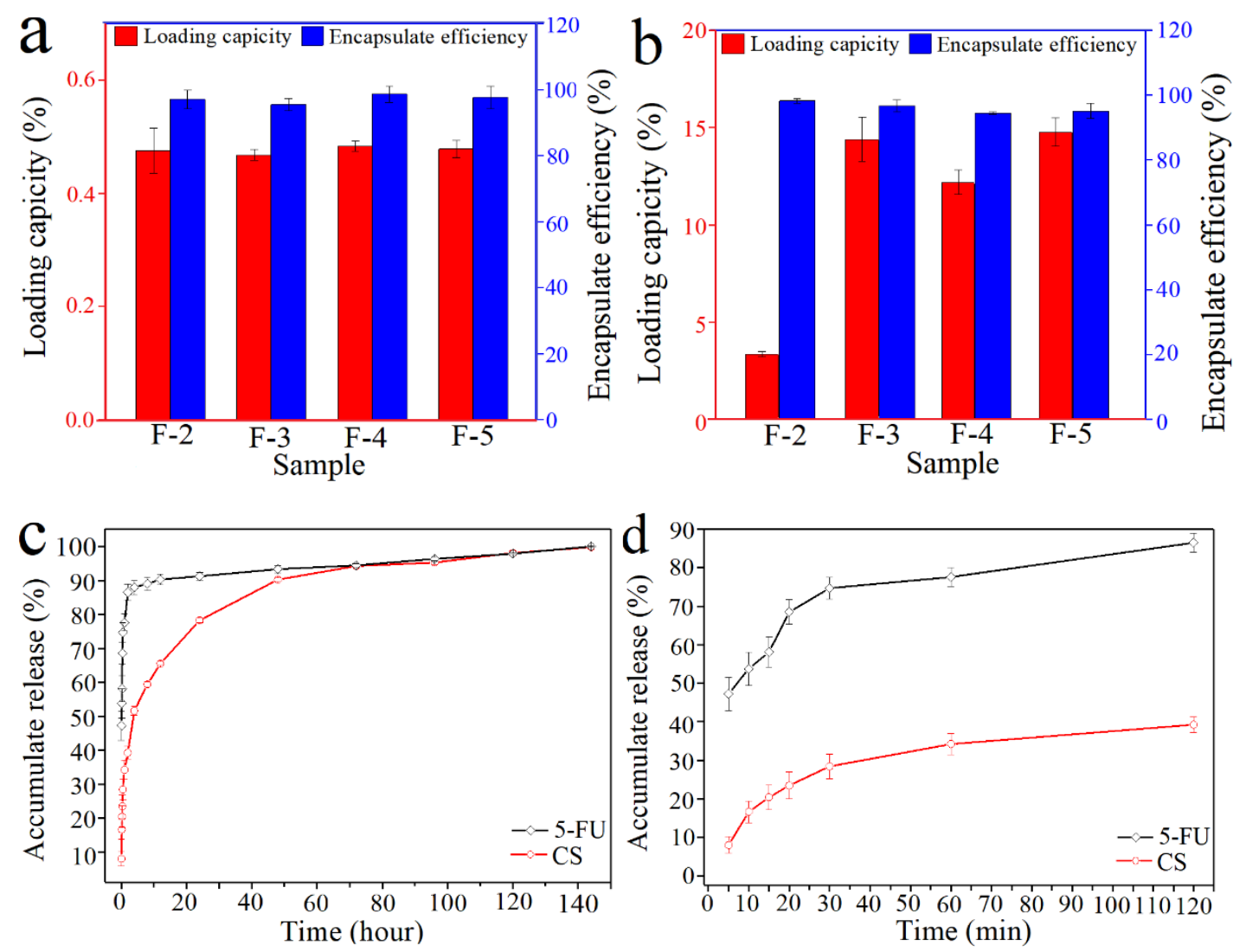

Fig. 6. 

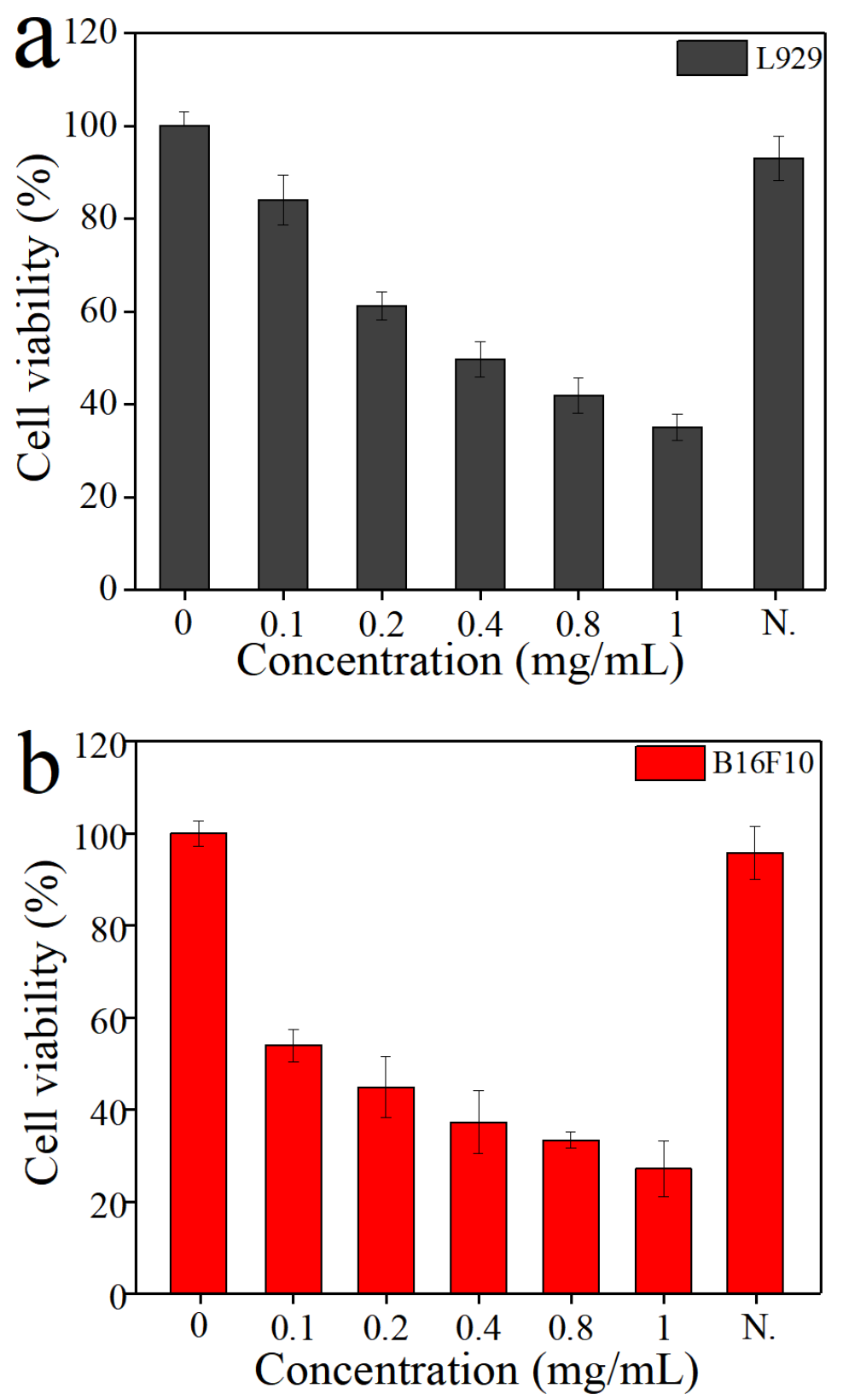

Fig. 7. 

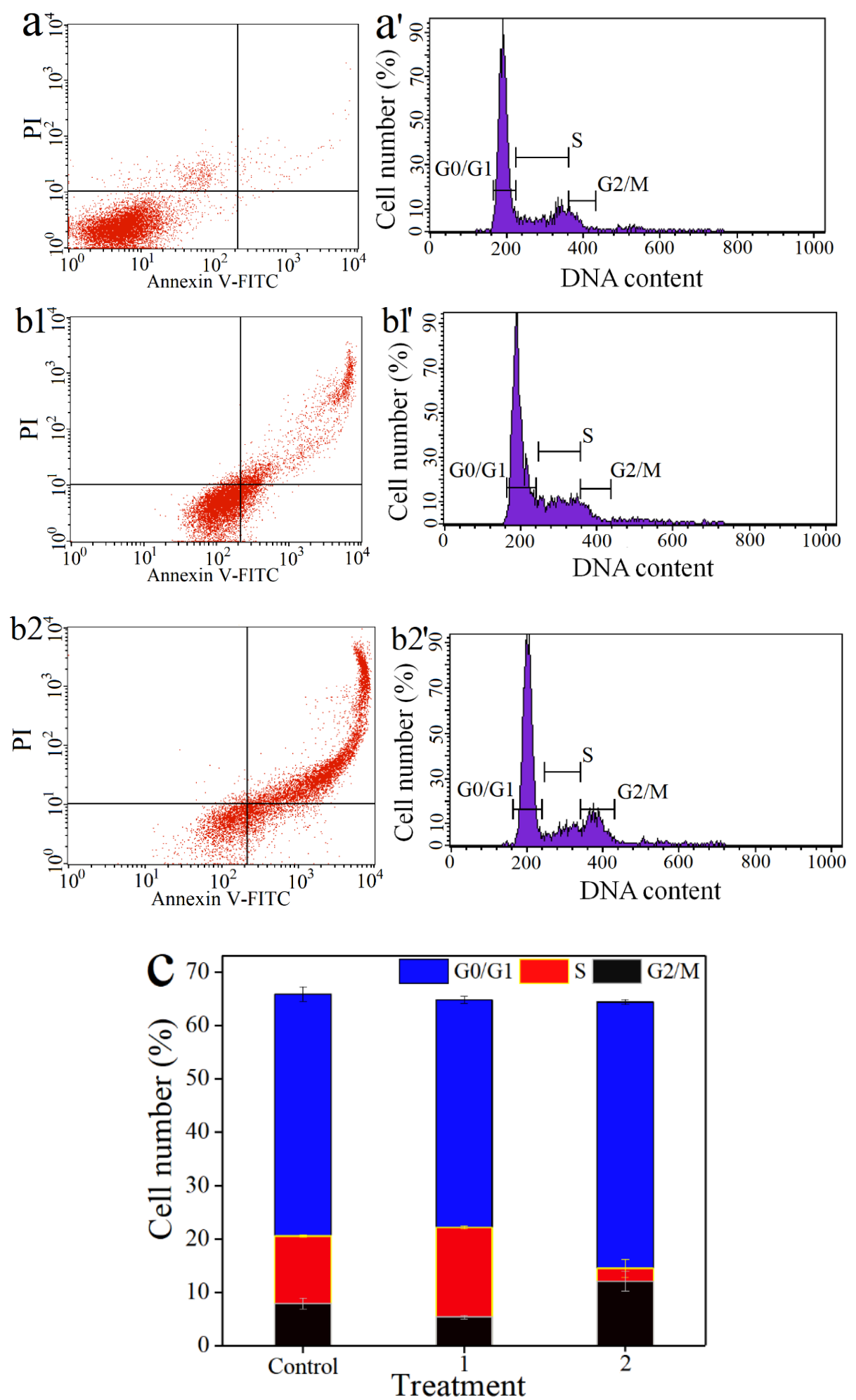

Fig. 8. 

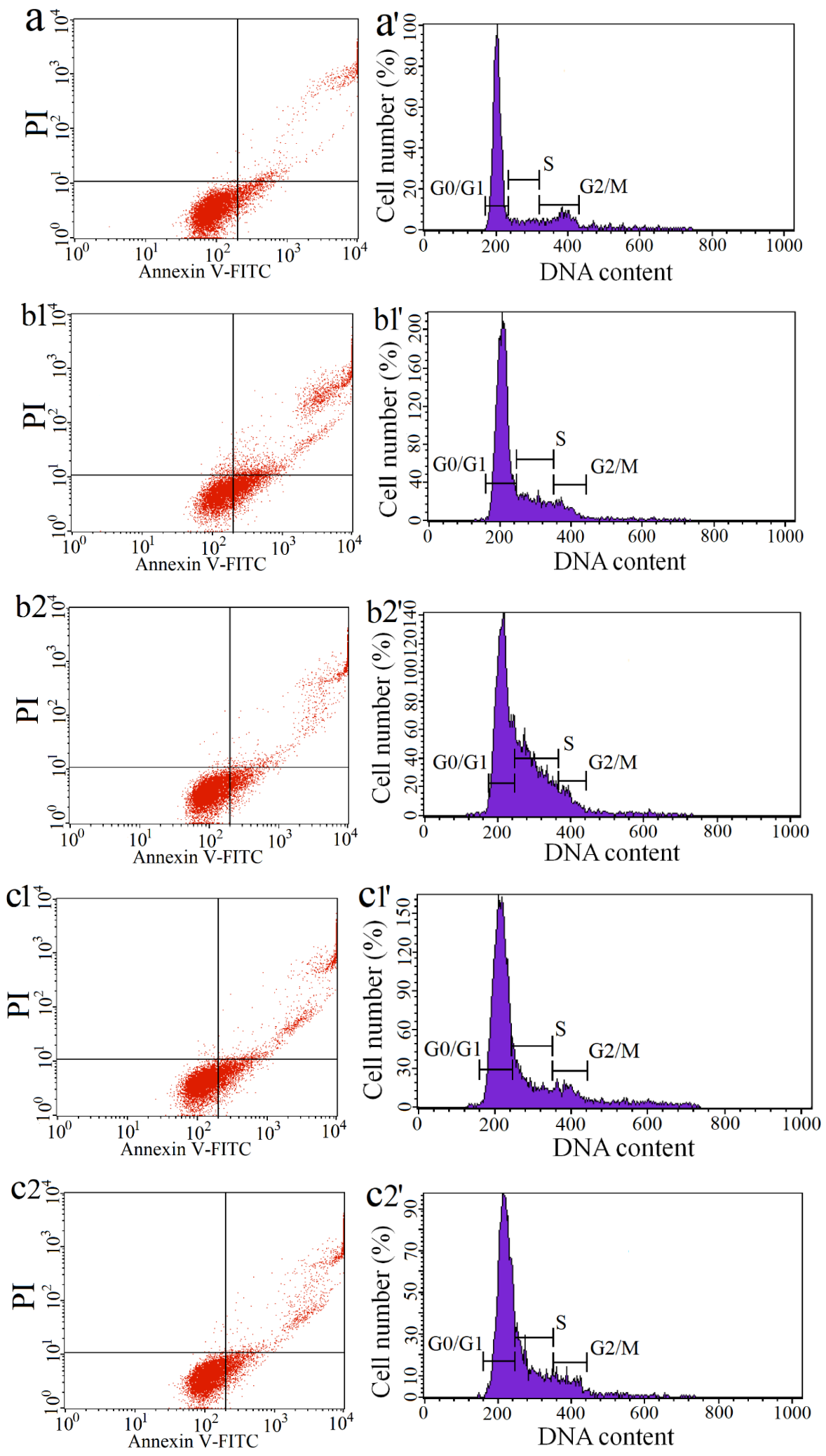


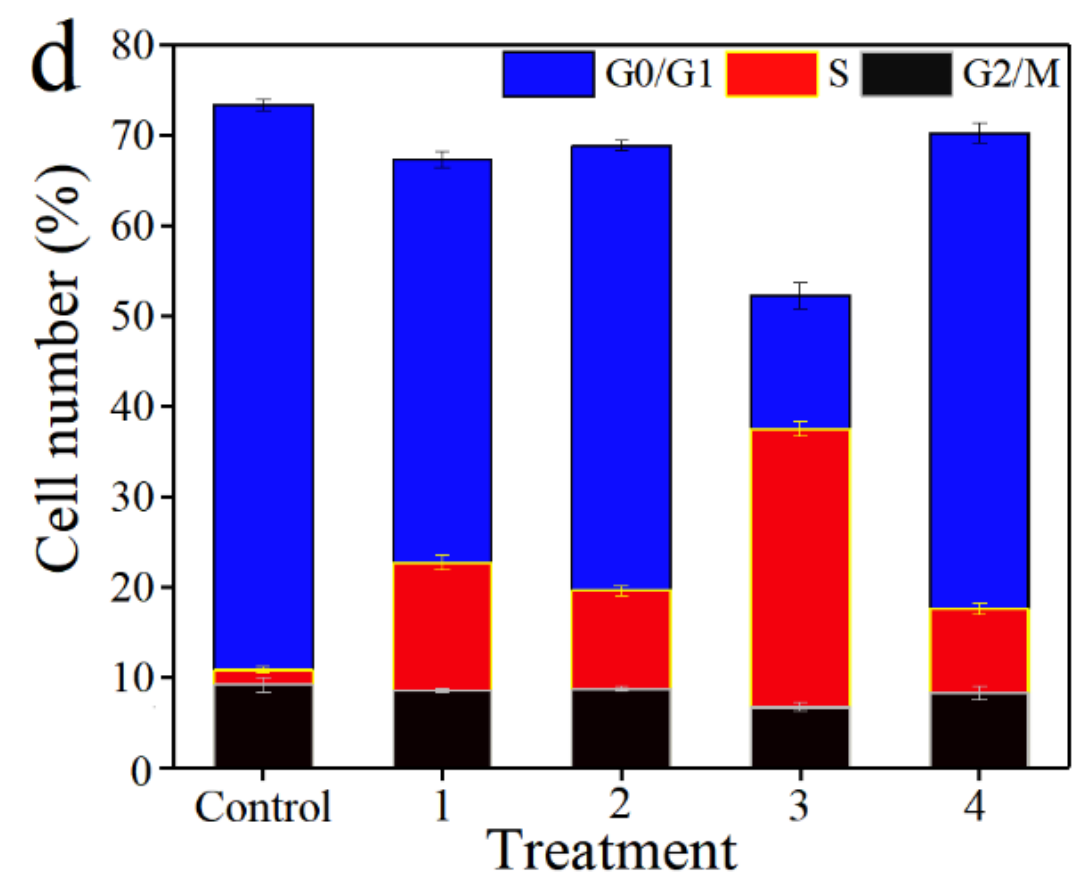

Fig. 9.
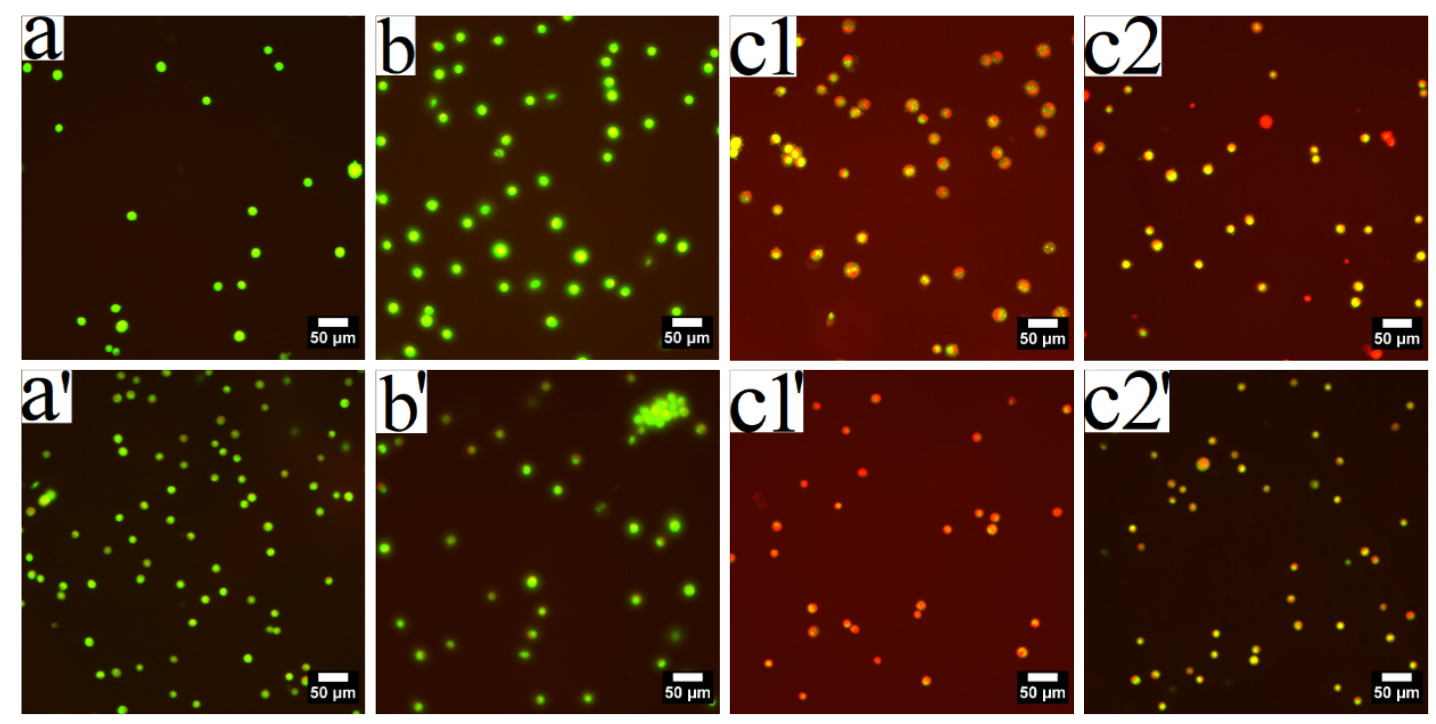

Fig. 10. 